\title{
LANGUAGE SKILLS AND THE NEW CURRICULUM
}

\author{
Ştefania Daniela GĂITĂNARU, \\ Teacher Şcoala Gimnazială Corbii Mari, Dâmboviţa, \\ Romania \\ E-mail: gaitanaru@yahoo.com
}

\begin{abstract}
The aim of this paper is to be the corollary of some applied lectures and of a permanent preoccupation of projection, of adaptation to the changes imposed by the actual educational policies, and furthermore to explore the current academic curriculum of Romanian language and literature and how it can be improved to better suit the development of the student. In the actual context, the academic curriculum generates a wide range of approach possibilities of content by using modern didactic strategies. Conscious learning of notions is reflected in the capacity of students of acquiring new information, in the development of investigation capacities and, especially, in applying the assimilated knowledge by respecting the fundamental principles of didactics. The scientific content considered in the academic curriculum is constituted from concepts, notions, Romanian language and literature knowledge, that the teacher has to recreate starting by consulting the current academic curriculum, thus adding a new analytical and interpretation vision. Mandatory contents from the academic curriculum can be approached with the aid of using modern means, such as applications or educational software, in different moments of the classes, because it streamlines and improves the instructiveeducational process. In the instructive-educational process, the analysis and operation of linguistic transformation is being followed together with the flexibility of the concepts, aiming to guide the students in how they should learn and even more, what to do with the accumulated knowledge, permanently following the preparation and development of the individual in European contexts. The modern teacher has to be in a partnership-like relation with his students, by negotiating the objectives of learning, the forms and methods of evaluation, as even himself is being subject to this transformation. He has to adapt to new rules, prove new competences, adopt different methodology strategies and relational behavior compared with the traditional school..
\end{abstract}

Keywords: curriculum; strategies; learning; behavior; softwares;

\section{INTRODUCTION}

During the compulsory schooling, the aim is to form a youngster with a basic communicational and literary culture, able to be understood and understand the world, to communicate and interact with his pers, to use efficiently and creatively his abilities towards solving day-by-day issues, to be sensible towards natural and man-made beauty.

Educational-instructive activities and promoting cultural models lead towards being aware of the communication act and supporting knowledge and correct use of Romanian language, in different and specific expression conditions.

Linguistic culture can not be inherited or bought, but rather built and reinforced. The scholar institutions and teachers have an important role in blending tradition and innovation, 
in teaching rules and exceptions from these, in accepting two or more methods of interpreting the same context, in blending notions related to form with notions related to function and in lecturing relevant literary texts from Romanian and universal literature.

During gymnasium classes, students have to slowly acquire the capacity to clearly orientate to research language facts, to discover essential traits of these in order to understand linguistic structure in speech and text, through excercising abstractization skills and through actively assimilating grammatical notions and definitions, but also their logic. Didactic research have proven that grammatical notions are abstractions that generalizes other abstractions reflected in relationships between words, relationship towards which thought, language and logic participates.

\section{THE CONCEIVING OF NEW ACADEMIC CURRICULUM}

The conceiving of new academic curriculum that aims towards forming new linguistic competences for students, but also to develop the rompanian language in diverse shapes: of spoken language - written or oral, literary or popular - rises a series of issues in establishing the content that should be considered in textboos, as a first important tool easily approached by students and teachers. Currently the interaction between three components its being observed: linguistic component (belonging to language sciences that assures the correct, conscious and efficient use of the language), the interrelational component (belonging to communication sciences that assures the social insertion of the individual) and the estetic and cultural component (belonging to literature as an art of the word, that assures the development of the human personality).

Conscious learning of notions is reflected in the capacity of students of acquiring new information, in the development of investigation capacitites and, especially, in applying the assimilated knowledge by respecting the fundamental principles of didactics.

The objectives of Romanian classes, generally, can be attained by understanding the need to study literary rules. Students need to be guided towards acknowledging that speaking correctly means being understood, conclusive and impressing.

Also, studying Romanian language has a major effect in developing critical thinking, observation skills, abstractization skills and analogy skills.

Romanian class curriculum is restructured in a manner in which contributes to increasing student's interests towards understanding Romanian language, acknowledging the necessity to study the literary norms and towards forming a patriotic sense by understanding that the language is the expression of the national living being and the richest communication form.

Language is a product of history and fulfills the purpose of main communication method and social activity. Inside language, different stuctures accumulates and settles, sometimes heterogeneous, having as a starting point the same values and functions.

As language and thinking are strongly linked and interrelated, however they are not identic phenomenons, they work in a binary manner, just as convergent mountains of communication. An idea worth mentioning is that whatever is transmitted or communicated is a message, an informational content, semantic, but at the same time a knowledge experience, a logical and social phenomenon. The word is tied to the sentecne, the concept ist ied to the judgement, these being the phenomenological expression of communicational experience and represents the arhitecture of an explanatory world.

It can be stated that grammatical norms, semantic relationships and logic norms are united and simmetrical. Therefore, between the communicational system, as a 
complementary function of semantics and grammar, from the perspective of communicational syntax, and the cognitive system there is a unity rapport that is being installed. Therefore, we can not think without the means of the language, and meaningless talk or cognitive content it is a shape without content.

Learning the language develops the affective side of the human personality, it outlines titudes, feelings and valuable judgments. In the process of acquisition, use and cultivation of language, linguistic structures have an important role through the fact that it uses the word as a constructing material of communication. The weight of knowledge that targets these structures is semnificative in textbooks from compulsory education system. These can influence linguistic manifestation at language level oral and written and language level popular-educated. The practice of literary language impose respecting unanimously accepted and acknowledged norms.

Learning the language represents at the same time freedom and constraint. Freedom because it allows eachother to express, affirm, understand the world and the oters, and furthermore, it is constraint because in order to communicate, it obliges the transmitter and receptor to respect laws and norms. From here it starts the organisation of language study around two fundamental types of didactic activities: communication practice and systematic study of language behavior, in a global vision of independence and equilibrum.

To all of these struggles, school answers through highlighting the lecture and text understanding, implying metalinguistic knowledge assimilation, but also practicing, chiseling them in diverse communication contexts, that can be found in the structure of assessment subjects at the end of the cycle.

Receiving correctly any type of message, correctitude, the flexibility of expression and the rigor and linguistic elegance through which the gate of civilization can be opened for each individual and becoming aware of lexicon particularities that mirror in the word.

\section{LANGUAGE SKILLS}

For students eager to progress and to perform, incorporating knowledge that targets working structres of Romanian langue in literature classes, in the understanding and analysis of literary/non-literary texts, leads towards a better retention, towards effortless obtaining the transfer, towards forming soem linguistic competences useful in forming their personality. Aspects of working linguistic structes requieres an uninterrupted effort and growing, especially through the lecture of literary texts.

The quality of the didactic process and of the level of academic results are determined by the quality of factors' action involved in the organization and development of educational activities and their functionality: internal factors (biopsychic condition of subjects) and external facotrs (inside which instruction-teaching activity is being conducted).

From the didactic perspective of Romanian language, of notion forming, of metalinguistic knowledge, it can be accomplished in four learning sequences, after the model formulated by Vistian Goia, in 1995, starting from the models created by R.M. Gagné, in 1975 and H. Klausmeier, in 1976: the conscious acquianting with the grammatical phenomenon, the analytical phase and distinguishing the grammatical plan from the logical one, the pase of appropriation of rules and definitions, the phase of fixing and superior operating of appropriated language notions (Goia, 2002, pp. 39-40).

Introducing the content unit constitutes a familiarization activity, one of conscious initiation of the student towards the language phenomenon considered, in our case, antonyms, that leads towards active perceiving and information accumulation. In this phase, antonymy 
is being learned, either through isolations, either through highlighting the new notion from one or more texts in order to follow with the analysis.

Intuiting the phenomenon from a series of concrete examples leads to shaping new representations, from here the intuitive character. The first phase of learning is conditionated by an existing attention state, an intelectual involvement, affective and volitional, that allows the understanding, penetrating and processing some notions, categories, principles such as fixating them in the memory, and in the end using them in new situations.

The second phase, the analytical one, of distinguishing the grammatical plan of the logical one, it is being conducted through anlysing the new notion and revealing the characteristics. The didactic process is conducted, through euristic conversion and anlysis, in order to assign some values, not the object designated through word, but rather the word as a formal unit of language that can enter in some relationshops, according to the context.

The third phase assumes assimilating the rules and definitions, the characteristics of the notions subject to analysis, concentrated in definitions, with support from thinking operations: comparison, calssification, generalisation, syntesis.

The las phase of the formation and fixation of linguistic structures process is a superior phase, of conscious operation with these : in different exercises, essays in class and home.

Mandatory contents from the academic curriculum can be approached with the aid of using modern means, such as applications, educational softwares, in different moments of the classes, because it streamlines and improves the instructive-educational process. Using softwares allows the student to work in his own rythm, to balance individual educational activities with teamwork activities, to receive instant feedback to their answers.

\section{EDUCATIONAL SOFTWARES}

Educational softwares can be used within the pale of Romanian language and literature calsses, follwing permanently the projection of the instructive-educational process, that will consider the preparation and development of the individual in a context that is in a state of perpetual change.

WALLWISHER represents a virtual notice board where short messages can be posted that contain texts, images and links (https://www. wallwisher.com/). It can be used for brainstorming, for posting useful Internet links, new words, terms or comments on a different theme. Mandatory lectures can be posted and furthermore be valued at the correct moment.

POTATOES includes six free applications for creating interactive tests: with simple answers, multiple answers, short answers, crosswords, paired words, ordering and phrase completition (http://hotpot.uvic.ca/). I consider that this type of softwares is efficient in different types of classes: of consolidation, of mixed nature and of knowledge evaluation.

BUBBLE.us is a simple application that allows creating conceptual collaborative online maps, through which students can create classifications that can be kept as images of html files (http://bubble.us/beta/). This application can be useful inside a class of knowledge fixation and systematization.

TEACHERTUBE allows hosting videos conceived by teachers with an educational purpose (http://teachertube.com). This software can be applied in a sequence of classes in order to capture students' attention. A fairy tale can be brought as an audio recording, interpreted by a famous actor, as part of a knowledge appropriation class. 
I consider that applying modern didactic means stimulates each individual and allows fitting into the new permanent education, but also adapting this at the rapid evolution of changes, in a world that offers unlimited possibilities.

In order to develop the cognitive horizon, the student has to pass through all forms of instruction: guided learning inside an organized institutional framework, in which teacher's presence is absolutely necessary, individual learning, independent, so later on the students can follow knowledge by themselves.

Capitalizing the generated potential by TIC usage in the complex act of teachinglearning-evaluation regarding Romanian language and literature, assures the responsability of the student in relation to itself, with its own training and imposes the development of a relationship with visible effects on knowledge, both short term and long term.

I find efficient the approach, actualization and development of linguistic structures from a transdisciplinary perspective, because it implies a sedimentation of some scientific experiences of other teachers, either during the class, as a didactic unit, either inside a didactic sequence. I consider applying transdisciplinary tests as being opportune, even marking tests from the perspective of correctitude, expression, spelling and informational content.

Organizing efficient educational situations assumes adopting and conceiving a didactic strategy that implies carefully selecting the didactic material, the methods, the procedures and the bibliography. The didactic strategy conceived implies rapporting to age particularities, to respecting didactic principles, but also a concrete learning situation used as a starting point for the teacher.

The current educational strategy aims towards making the teacher responsible in conceiving the didactic approach according with the academic curriculum in an optimal manner for his students, having the purpose of facilitating the reporting phase and accesing some defining elements of national and universal patrimony, conceiving creative papers in scholar and extra-scholar contexts, participating to cultural projects and events organized in formal and informal contexts.

In the instructive-educational process the analysis and operation of linguistic transformation is being followed, together with the flexibility of the concepts, aiming to guide the students in how they should learn and even more, what to do with the accumulated knowledge, permanently following the preparation and development of the individual in an European contexts.

The professor is assigned with the task of organizing a complex act of schooling that assures the accountability of the student in rapport with himself and with his own training and imposed the development of a relationship with visible effects both long term and short term over knowledge. The change comes once with the academic curriculum from Romanian language and literature class for gymnasium students. It considers documents such as: European Parliament Recommendation regarding key-competences; European Framework for studying foreign literature at secondary education (LIFT 2); European Portfolio of languages etc., the curriculum brings to foreground the three integrated components that the mentioned course: linguistic competence, interrelated, and the esthetic and cultural component.

Therefore, the curriculum is subordinated to the new educational paradigm and targets: adapting to the national sociocultural architecture in conjunction with the universal one; the transdisciplinary opening for touching educational ideas, reflected in the profile of the gymnasium graduate and not last, the correlation with the curriculum for Romania's 
maternal language and literature classes. The teacher must help students to understand the necessity of knowing multiple languages and to integrate them in different cultures.

In current society, it has been promoted the use of at least one European language, and children has to keep up with social evolution. A first objective of intercultural education consists of instructing individuals towards understanding, accepting and respecting diversity. The importance of this side of education is of allowing a fast adaptation of individuals to different circumstances.

The modern teacher has to be in a partnership-like relation with his students, by negotiating the objectives of learning, the forms and methods of evaluation, as even himself is being subject to this transformation.

He has to adapt to new rules, to prove new competences, to adopt different strategies of methodology and relational behavior compared with the traditional school. We are all actors in the social life. We assume ore impose roles, forced by contexts. And the professor, as a consequence, will have to obey to new customs in order to match the consumerism society.

The professor has to take into account the elements characteristic to modern society, the fact that students live in a media supersaturated society, in which the products of media culture offers the base for conversation, the support of life and their fantasies. The visual and audio forms of media culture replace the written forms and they require a new type of media "literacy". The act of communication becomes efficient when favors an active engagement from the student, an engagement with all its intellectual and affective forces. Therefore, receiving overcomes the simple perception of some heard content. To produce active interlocutors, to determine the students to follow with interest and manifest an active attitude at classes, represents an indicator of pedagogic competences related to the teacher.

Additionally, the media culture has become a dominant force of socialization, images and disseminated celebrities replacing the traditional family, school and Church, proposing new identification models and producing resonant images in style, trend and behavior. Learning is not a mechanical process of accumulating knowledge, the same for everyone, but rather is a process determined by the significance that the student attributes to the information. The purpose of the teacher is to be a median between external standards, predetermined and student's needs, interests and wishes.

In organizing an educational system centered on the kid, the teacher becomes a coparticipant of the student to the conducted activities. He accompanies and guides the kid on the road of knowledge. Using interactive methods of teaching-learning-evaluation in the didactic activity contributes to improving the quality of the instructive-educational process, having an active-participant character and a true active-formative value over the personality of the student.

In the modern school, the base dimension according to which the educational methods are being considered is their active character, meaning the measure in which they are capable of triggering the engagement of students in activity, practical or mental, to stimulate their motivation, cognitive and creative capacities. The interactive methods motivates the students, they offer a special affective charge. Through interactive group methods, children exercise their capacity to select, combine, learn new things that they will need in their academic and adult life.

As a condition of the new curriculum, the lecture of the curriculum and of the textbooks is not linearly mandatory. The curriculum has to be crossed by everyone, but the curriculum, just as the textbooks, fits a personal and adapted read. Over the content of the 
curriculum, the teacher can intervene by regrouping them under the established themes. Over some units or elements of content from the textbook, the teacher can intervene in different manners - adaptation, replacement, omission, addition - or can use other support materials. The projection of evaluation activities is being conducted at the same time as the projection of the teaching-learning process and fully matching with it. Some useful questions are being imposed regarding the projection of evaluation tools: Which are the competences of the academic curriculum that the students have to acquire?; Which are the minimal, medium and superior competences that the students can achieve in order to prove that they have met these objectives?; Which is the specific of the student collective for which I project the evaluation?; When and with what purpose do I evaluate?; What type of evaluation should I chose?; With what tools can I conduct the evaluation?' How will I proceed for each student to be evaluated through tests as various as possible, so the evaluation can be objective?; How will I use the data provided by the evaluation tools in order to eliminate the eventual blockages?; The evaluation should assure a highlight of the progress recorded by the student in rapport with himself on the road of meeting the objectives mentioned in the curriculum. It is important to be evaluated not only the quantity of information that the student has, but especially what he can do with what he knows.

A modern education, well outlined, allows initiative, spontaneity and creativity, but also routing, guiding, and teacher's role acquires new valencies, overcoming the traditional view in which the teacher was a mere information distributor.

\section{CONCLUSION}

Organizing the educational act has to be done in perfect correlation with the current educational policies and trends, and to include accordingly changes that target the Romanian Language and Literature curriculum from the gymnasium cycle, focusing on oral communication, communication construction elements and intercultural elements.

Currently it is being followed the interaction between three components: linguistic (which belongs to language sciences that ensures a correct, conscious and efficient use of the language), interrelationa (which belongs to communication sciences that ensure the social insertion of the individual), estetic and cultural (which belongs to literature as the art of the word and it ensures the complex development of the human personality).

As a teacher of Romanian Language and Literature, I follow facilitating the reception of any type of message, the correctness and suppleness of expression, the rigor and linguistic elegance through which the gate of civilization can be opened, in order to facilitate the reporting and accessing of some defining elemnts of the national and universal heritage, the making of creative papers in scholar and extra-scholar contexts, the participation in projects and cultural events organized in formal and informal contexts.

In the instructive-educative conduct, I have as a general purpose the analysis and operation of linguistic tranfosrmations and concept elasticity in order to guide the students in their learning process and how to use what they have learned.

The organization of a complex instruction act has to be permanently followed in order to ensure the responsibilization of the student in relation with himself, with his own formation and that imposes the development of a relation with vizible effects - long term and short term. 


\section{BIBLIOGRAPHY:}

[1] Goia, V. (2002). Didactica limbii și literaturii române pentru gimnaziu și liceu. Cluj-Napoca: Editura Dacia Educational.

[2] Dumitriu Lupan, N., Rusu, M.-M., Preda, L.E., Lascăr, M., Anton, C.E., Burlacu Mercedes, C. \& Agapin, L. Competenţe-cheie TIC în curriculum şcolar, disciplina limba şi literatura română. 16-18. https://kupdf.net/download/suport-curs-lb-romana-final_5af97edce2b6f5982f00c55a_pdf.

[3] Ministerul Educaţiei, Cercetării şi Inovării. (2009). Programe şcolare pentru clasele V-VIII. Aria curriculară: limbă şi comunicare. Bucureşti. https://www.isjcta.ro/wpcontent/uploads/2013/06/Programa-limba_si_literatura_romana 5-81.pdf.

[4] https://www. wallwisher.com/.

[5] http://hotpot.uvic.ca/.

[6] http://bubble.us/beta/.

[7] http://teachertube.com. 